\title{
The Forgotten “Weed” Allergy: A Case Report of Fresh-Food Skin Prick Testing as a Model for Evaluating Allergy in a Patient with Cannabis-Induced Urticaria
}

William Keefe ${ }^{1 \dagger}$, Justin Chin ${ }^{2 *}$ and Mary Lee-Wong ${ }^{3,4 \dagger}$

Correspondence: justinchindo@gmail.com

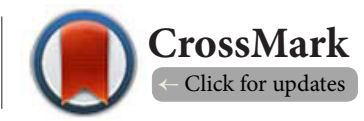

'These authors contributed equally to this work.

${ }^{1}$ Mount Sinai Beth Israel Medical Center, Department of Internal Medicine, New York NY-USA.

${ }^{2}$ Lifelong Medical Care, Department of Family Medicine, Richmond, CA-USA.

${ }^{3}$ Mount Sinai Beth Israel Medical Center, Chief of Allergy and Immunology, Department of Internal Medicine, New York NY-USA.

${ }^{4}$ Icahn School of Medicine at Mount Sinai, Clinical Associate Professor of Medicine, Department of Medicine, New York NY-USA.

\begin{abstract}
Background: Cannabis sativa, more commonly known as marijuana, use has steadily increased in the past decade with increasing decriminalization and acceptance among the United States population. More than $20 \%$ of Americans state that they have either tried or currently use marijuana in their lifetime. Subsequently, the rates of allergic reactions associated with cannabis handling, ingestion, and utilization have also risen by association.

Case Presentation/Methods: 53-year-old Black male presented to the outpatient allergy clinic with a case of suspected cannabis induced urticaria status post contact with dried cannabis, with red raised rashes. The rashes would appear whenever he handled dried cannabis and spontaneously self-resolve. Due to the lack of formal guidelines in cannabis allergy testing, he was evaluated using fresh-food skin prick testing, which revealed positive reaction to his cannabis sample. Management and counseling were provided to the patient in regards to allergy prophylaxis and symptom treatment.

Discussion/Results: Increasing prevalence of cannabis allergies have informed the contemporary need to develop standardized protocols for testing. The lack of commercially-prepared skin prick testing necessitated the creation of a fresh-food derived skin prick testing protocol for this patient.

Conclusion: Limited research and testing protocols currently exist for the diagnosis and treatment of cannabis allergies due to continuing federal restrictions and ethical considerations. As cannabis use becomes more commonplace, the development of standard procedures is necessary to ensure that patients are being adequately assessed.
\end{abstract}

Keywords: Cannabis, marijuana, allergy, fresh food testing, skin prick testing

\section{Introduction}

Cannabis sativa is an annual, flowering plant that has been cultivated and consumed for its psychoactive properties throughout recorded history [1]. Upon isolation of the primary active component of tetrahydrocannabinol (THC) and its effects on cannabinoid receptors in the brain, mounting pressure for the regulation of marijuana's production and use occurred in the United States during the early $20^{\text {th }}$ century $[2,3]$. Despite initial opposition due to potential medicinal and psychological benefits, increasing restrictions culminated in federal illegalization $[2,4]$. Further studies on its utility in pain management spurred a countermovement, with focus on the medical, and subsequently recreational, use of marijuana $[5,6]$. At present, there are 33 states permitting medical use of marijuana and 11 states permitting recreational use [7].

Sensitivity reactions to marijuana range widely from selflimited symptoms such as conjunctival injection and generalized pruritis to more urgent presentations such as dyspnea, 
urticaria, and anaphylaxis [9]. The illicit nature of cannabis use-and associated social stigma-has posed innumerable barriers to reliable patient reporting, development of testing protocols, and care $[\mathbf{9}, \mathbf{1 0}]$. Skin-prick testing (SPT) has remained the most common method for diagnosing atopic (i.e. IgE mediated) sensitivity, with two main methods of sample preparation: commercially-prepared skin prick testing (CSPT) and fresh-food derived skin prick testing (FFSPT) [11]. CSPT is currently unavailable due to federal restrictions on marijuana, which leaves FFSPT as the primary method for allergy testing. The dilemma for physicians, however, emerges with navigating state laws vis-à-vis federal legislation in the vacuum of objective, standardized testing protocols $[2,3,12]$. Here we present a case of marijuana contact allergy and review the protocols, challenges, and ethical considerations associated with marijuana FFSPT.

\section{Case presentation}

A 53-year-old Black male with past medical history of HIV and chronic recreational marijuana use presented to the outpatient allergy clinic for several year history pruritic hives following direct physical contact with dried marijuana. The hives appeared on his hands within five minutes of direct contact and the patient reported that episodes have become more pruritic, lasted longer, and occurred more frequently with subsequent exposures. The rashes were described as raised, erythematous, circular lesions that last 3-4 hours after an exposure to marijuana plant material and self-resolved. Oral diphenhydramine has been used in the past to occasionally improve pruritic symptoms. He did not recall any reactions following inhalation and has never ingested marijuana in its raw or cooked form.

Of note, the patient reported remote history of hospitalization for anaphylaxis to an American seasoning mix Mrs. Dash following the oral ingestion. He had deferred allergy testing at that time, but was now concerned about whether he could develop a similar reaction with marijuana. Social history positive for chronic marijuana use, with 1-2 joints per day. No pertinent family, surgical, or psychiatric history. Vitals and physical exam were unremarkable.

Risks and benefits of SPT were discussed with the patient and he wished to proceed. A marijuana sample was provided by the patient and a solution was prepared for SPT using the FFSPT technique of serial dilution (Figure 1). For the initial preparation, $1 \mathrm{~g}$ of solid marijuana plant material was hydrated in $10 \mathrm{~mL}$ of normal saline, by which the plant matter was strained and $1 \mathrm{cc}$ was taken to produce four serial 10-fold dilutions in normal saline from 1:10 to 1:10,000. The initial marijuana sample was hydrated for 30 minutes before extraction. The relative purity of the initial marijuana sample was indeterminable, however the patient subjectively noted that he obtained his marijuana from "a good source". The volar aspect of the patient's right arm was labeled " $\mathrm{H}$ " for histamine, "NS" for normal saline, "1-5" for the corresponding dilution samples. SPT revealed $4 \mathrm{~mm}$ induration with " $\mathrm{H}$ " positive control, negative reaction with "NS" negative control. Positive findings that progressively increased in size with increasing concentration of marijuana dilutions were visualized, with the largest measuring $7 \mathrm{~mm}$ (Figure 2). The patient was continuously monitored throughout the testing period and experienced no other adverse reaction other than localized induration, erythema, and pruritis similar to previous marijuana exposure.

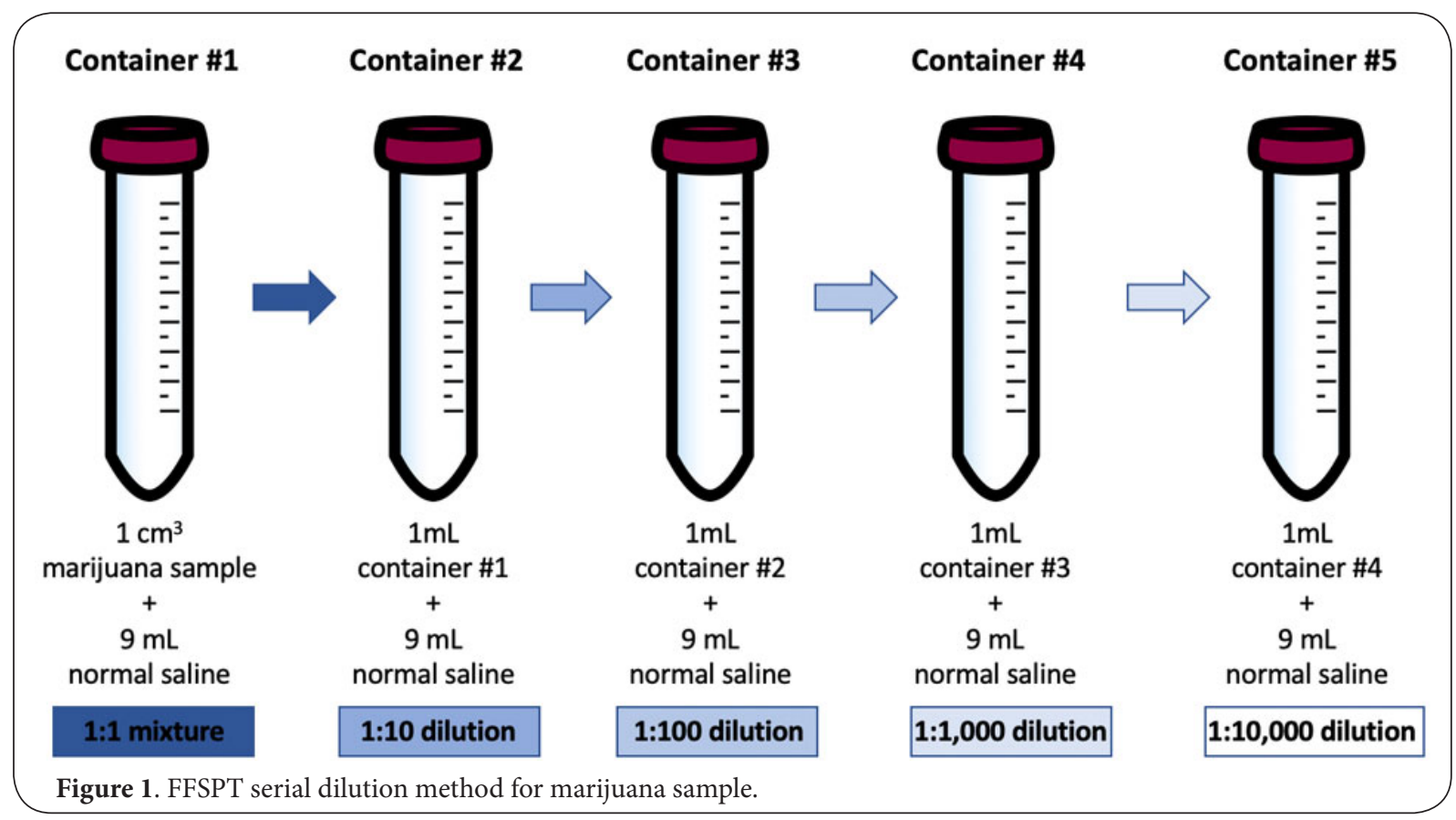




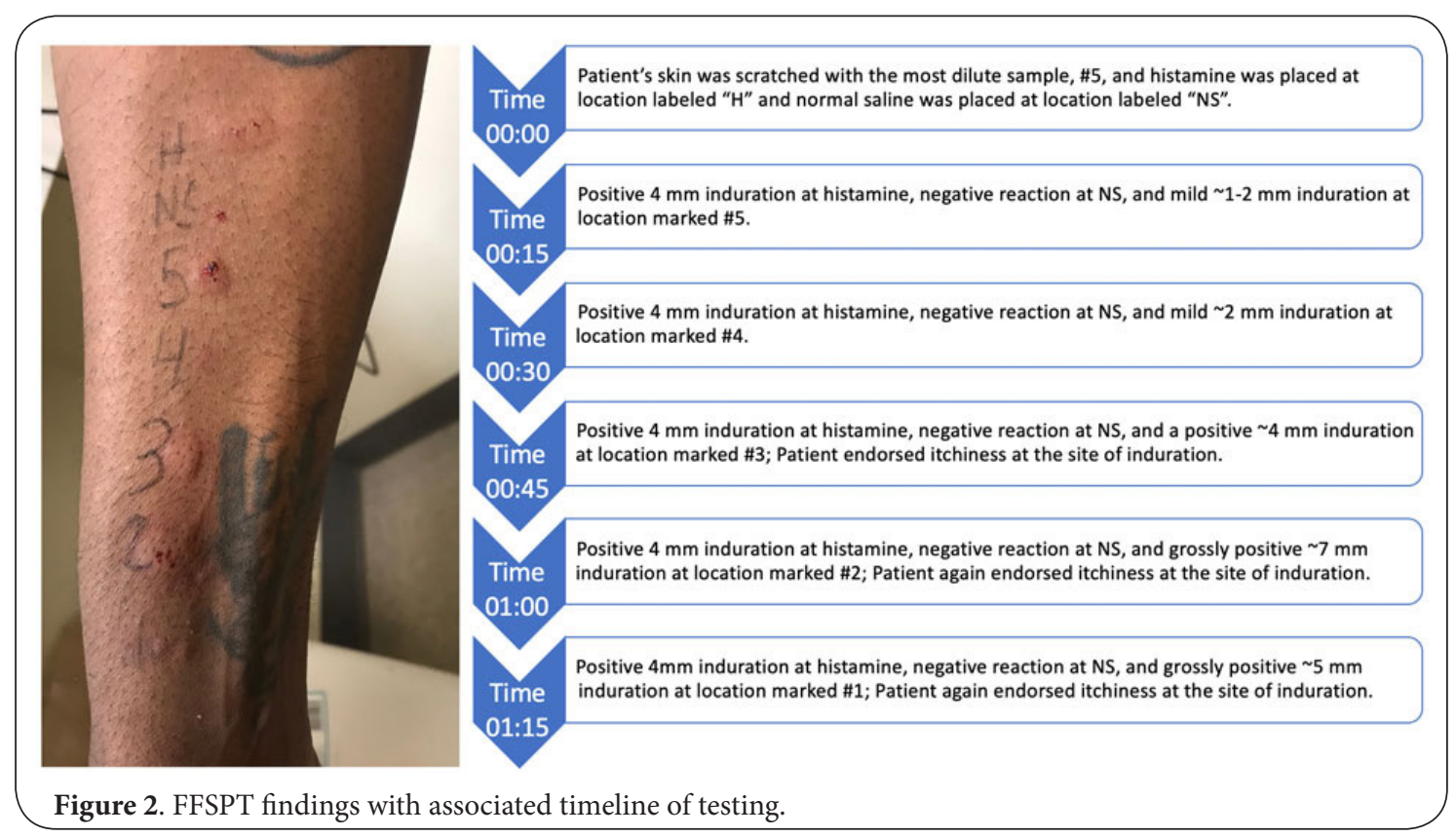

\section{Discussion}

Increasing prevalence of cannabis allergies have informed the contemporary need to develop standardized protocols for testing. Prior studies have estimated 8-10\% of the United States population may have cannabis allergies compared to recent research showing upwards of $20 \%$, particularly in states that have legalized medical and recreational marijuana use [13-15]. History elicitation may be difficult as patients may intentionally be evasive due to concerns of illegality and criminalization, social stigma of perceived drug use, and fear of adverse perception $[10,15]$. While history gathering and ethics were not an issue, two barriers present in this case were identified as: 1) a lack of commercial preparations for cannabis SPT and 2) the paucity of literature supporting an effective method for testing.

The lack of CSPT necessitated the creation of a FFSPT testing protocol for this patient. FFSPT for cannabis allergies has been documented, however the steps in preparation and technique are limited at best, especially when compared

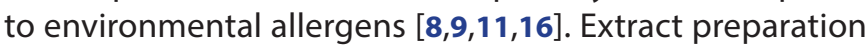
and testing were completed only after two preconditions were met: a detailed history and patient-provided sample of substance that precipitated an allergic reaction. History taking was of utmost importance when determining the risk of severe allergic reaction during testing, as the patient reported having many prior episodes of hives when the "pure" undiluted substance was exposed to skin, but no severe, fullbody, anaphylactic-type symptoms with exposure. Despite the relative safety of SPT in assessing atopic sensitivity, a proper history allows the preparation of a safe starting dilution and estimation of the likelihood of anaphylaxis [11].

A primary limitation of this case presentation is the omission of testing the cannabis sample on a non-symptomatic individual to make certain the any response is not an irritant response. Due to the restrictions of the hospital institution and ethics surrounding cannabis procurement, this can be a future area to be explored pending legalization and acceptance. An additional consideration regarding the emerging necessity for cannabis allergy testing is the increasing number of potential allergens cited in the literature that comprise cannabis preparations. THC has remained the primary suspected allergen as seen in passive-transfer studies and gas-chromatography [9]. However, more recent investigations have proposed Cans-3, nonspecific lipid transfer protein as a potential allergic substance [17]. Other suspected cannabis allergens include profilins, poly-galacturonase, thaumatin-like proteins, and RuBisCO photosynthetic enzyme $[\mathbf{1 0}, \mathbf{1 8}]$. Greater research is needed to further elucidate the etiology of cannabis allergies to create more targeted treatments.

\section{Conclusion}

This study highlighted the emerging need for cannabis allergy testing and the many barriers to evaluation and testing. FFSPT was proposed as a relatively effective, timely, cost-efficient method of preparation, however, more data regarding cannabis allergy testing is both warranted and needed. For the case patient, his history and results suggested a high likelihood of sensitization to cannabis in the dried, raw form- and thus was advised to abstain from using cannabis products.

\section{List of abbreviations}

CSPT: Commercially-prepared skin prick testing

FFSPT: Fresh-food derived skin prick testing

SPT: Skin prick testing

THC: Tetrahydrocannabinol 
Chin et al, Journal of Allergy and Asthma 2020,

\section{Competing interests}

The authors declare that they have no competing interests.

Authors' contributions

\begin{tabular}{|l|c|c|c|}
\hline Authors' contributions & WK & JC & MLW \\
\hline Research concept and design & $\checkmark$ & $\checkmark$ & $\checkmark$ \\
\hline Collection and/or assembly of data & $\checkmark$ & -- & $\checkmark$ \\
\hline Data analysis and interpretation & $\checkmark$ & $\checkmark$ & $\checkmark$ \\
\hline Writing the article & $\checkmark$ & $\checkmark$ & $\checkmark$ \\
\hline Critical revision of the article & $\checkmark$ & $\checkmark$ & -- \\
\hline Final approval of article & $\checkmark$ & $\checkmark$ & $\checkmark$ \\
\hline Statistical analysis & -- & $\checkmark$ & $\checkmark$ \\
\hline
\end{tabular}

Acknowledgement and funding

The authors have not declared a specific grant for this research from any funding agency in the public, commercial or not-for-profit sectors.

\section{Publication history}

Editor: Donald W. Cockcroft, University of Saskatchewan, Canada. Received: 08-Apr-2020 Final Revised: 04-June-2020

Accepted: 16-June-2020 Published: 25-June-2020

\section{References}

1. Malingre T, Hendriks $H$, Batterman $S$, Bos R and Visser J. The essential oil of Cannabis sativa. Planta Med. 1975; 28:56-61. | Article | PubMed

2. Mead A. Legal and Regulatory Issues Governing Cannabis and CannabisDerived Products in the United States. Front Plant Sci. 2019; 10:697. | Article | PubMed Abstract | PubMed FullText

3. O'Connor SM and Lietzan E. The Surprising Reach of FDA Regulation of Cannabis, Even After Descheduling. Am Univ Law Rev. 2019; 68:823-925. I PubMed

4. Eddy M. Medical Marijuana: Review and Analysis of Federal and State Policies. Congressional Research Service. 2010.

5. Borgelt LM, Franson KL, Nussbaum AM and Wang GS. The pharmacologic and clinical effects of medical cannabis. Pharmacotherapy. 2013; 33:195-209. | Article | PubMed

6. Whiting PF, Wolff RF, Deshpande S, Di Nisio M, Duffy S, Hernandez AV, Keurentjes JC, Lang S, Misso K, Ryder S, Schmidlkofer S, Westwood M and Kleijnen J. Cannabinoids for Medical Use: A Systematic Review and Meta-analysis. JAMA. 2015; 313:2456-73. | Article | PubMed

7. Wheeler JS andHagemann T.M. Medical marijuana in the United States: Historical perspectives, legal considerations, and professional obligations of the pharmacist. Journal of the American College of Clinical Pharmacy. 2018; 1:9-15.

8. Decuyper, II, Van Gasse AL, Cop N, Sabato V, Faber MA, Mertens C, Bridts $\mathrm{CH}$, Hagendorens MM, De Clerck L, Rihs HP and Ebo DG. Cannabis sativa allergy: looking through the fog. Allergy. 2017; 72:201-206. | Article | PubMed

9. Armentia A, Castrodeza J, Ruiz-Munoz P, Martinez-Quesada J, Postigo I, Herrero M, Gonzalez-Sagrado M, de Luis D, Martin-Armentia B and Guisantes JA. Allergic hypersensitivity to cannabis in patients with allergy and illicit drug users. Allergol Immunopathol (Madr). 2011; 39:271-9. | Article | PubMed

10. Ocampo TL and Rans TS. Cannabis sativa: the unconventional "weed" allergen. Ann Allergy Asthma Immunol. 2015; 114:187-92. | Article | PubMed

11. Ortolani C, Ispano M, Pastorello EA, Ansaloni R and Magri GC. Comparison of results of skin prick tests (with fresh foods and commercial food extracts) and RAST in 100 patients with oral allergy syndrome. J Allergy Clin Immunol. 1989; 83:683-90. | Article I PubMed

12. Min JY and Min KB. Marijuana use is associated with hypersensitivity to multiple allergens in US adults. Drug Alcohol Depend. 2018; 182:74-77. | Article | PubMed
13. Carliner H, Brown QL, Sarvet AL and Hasin DS. Cannabis use, attitudes, and legal status in the U.S.: A review. Prev Med. 2017; 104:13-23. | Article | PubMed Abstract | PubMed FullText

14. Hasin DS, Saha TD, Kerridge BT, Goldstein RB, Chou SP, Zhang H, Jung J, Pickering RP, Ruan WJ, Smith SM, Huang B and Grant BF. Prevalence of Marijuana Use Disorders in the United States Between 2001-2002 and 2012-2013. JAMA Psychiatry. 2015; 72:1235-42. | Article | PubMed Abstract | PubMed FullText

15. Wilkinson ST, Yarnell S, Radhakrishnan R, Ball SA and D'Souza DC. Marijuana Legalization: Impact on Physicians and Public Health. Annu Rev Med. 2016; 67:453-66. | Article | PubMed Abstract | PubMed FullText

16. Decuyper, II, Faber MA, Lapeere H, Mertens C, Rihs HP, Van Gasse AL, Hagendorens MM, Sabato V, Bridts CH, De Clerck L and Ebo DG. Cannabis allergy: A diagnostic challenge. Allergy. 2018; 73:1911-1914 . | Article | PubMed

17. Aizpurua-Olaizola O, Omar J, Navarro P, Olivares M, Etxebarria N and Usobiaga A. Identification and quantification of cannabinoids in Cannabis sativa $L$. plants by high performance liquid chromatographymass spectrometry. Anal Bioanal Chem. 2014; 406:7549-60. | Article | PubMed

18. Gamboa P, Sanchez-Monge R, Sanz ML, Palacin A, Salcedo G and DiazPerales A. Sensitization to Cannabis sativa caused by a novel allergenic lipid transfer protein, Can s 3. J Allergy Clin Immunol. 2007; 120:1459-60. | Article | PubMed

\section{Citation:}

Keefe W, Chin J and Lee-Wong M. The Forgotten "Weed" Allergy: A Case Report of Fresh-Food Skin Prick Testing as a Model for Evaluating Allergy in a Patient with Cannabis-Induced Urticaria. J Allergy Asthma. 2020; 7:1.

http://dx.doi.org/10.7243/2054-9873-7-1 